\title{
Direitos Humanos e Cultura Policial na Polícia Militar do Estado do Paraná
}

\author{
GLEBER DA SILUA LOPES" \\ EDNALDO APARECIDO RIBEERO" \\ MARGOS ANTONIO TORDORO"
}

\section{Resumo}

Há no Brasil uma carência de estudos sobre cultura policial. Os poucos trabalhos existentes são frutos de pesquisas qualitativas que enfrentam dificuldades para captar variações não aleatórias nas dimensões dessa cultura. Este trabalho procura contribuir para o preenchimento destas lacunas por meio de um estudo de survey com os policiais militares do Estado do Paraná. O foco recai sobre um dos aspectos da cultura policial que é caro à realidade brasileira: as atitudes e visões acerca dos direitos humanos. Como os policiais da PMPR veem os direitos humanos? Eles compartilham visões homogêneas ou há variações dentro da corporação? O trabaIho procura responder essas questões e testar três hipóteses: a de que os policiais militares paranaenses partilham visões mais desfavoráveis do que favoráveis aos direitos humanos; a de que os policiais mais velhos são mais resistentes aos direitos humanos do que os policiais mais novos; e a de que os não-oficiais e policias que trabalham no nível da rua compartilham uma cultura ocupacional mais avessa aos direitos humanos do que os oficiais e policiais em atividades administrativas. Os dados mostram que predomina na PMPR atitudes de rejeição aos direitos humanos. Como previsto, essa rejeição é maior entre os não-oficiais e policiais de rua. Todavia, descobriu-se que os policiais mais jovens são os que mais rejeitam os direitos humanos. As implicações desses achados são discutidas.

Palavras-chave: Polícia Militar. Direitos humanos. Cultura policial. Estado do Paraná.

\footnotetext{
* Universidade Estadual de Londrina (Brasil)

** Universidade Estadual de Maringá (Brasil)

*** Universidade Estadual de Maringá (Brasil)
} 


\title{
Human rights and police culture within Military Police of Paraná State
}

\begin{abstract}
Studies on police culture are scarce in Brazil. The few existing works result from qualitative researches that face difficulties for capturing not random variations in the dimensions of this culture. This paper aims to help fill these gaps through a survey study with the Paraná State Military Police. The focus is on one aspect of police culture that is relevant to the Brazilian reality: attitudes and views on human rights. How do police agents of the PMPR see human rights? Do they share homogeneous views or there are variations within the Police institution? The paper seeks to answer these questions and test three hypotheses: that the military police agents in Paraná share rather unfavorable views of human rights; that older police agents are more resistant to human rights than younger ones; and that non-commissioned officers and police agents who work at street level share an occupational culture more averse to human rights than the commissioned officers and police agents involved in administrative activities. Collected data show that attitudes of rejection towards human rights are predominant in PMPR. As expected, this rejection is higher among non-commissioned officers and street police agents. However, the highest rates of rejection to human rights considerations were found among the younger police agents. The implications of these findings are discussed.
\end{abstract}

Keywords: Military police. Human rights. Police culture. State of Parana. 


\section{Introdução}

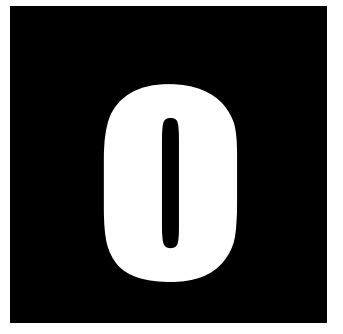

respeito aos direitos humanos por parte das organizações policiais brasileiras tem sido objeto de preocupações políticas e acadêmicas desde a redemocratização. A transição do regime autoritário para o regime democrático foi marcada por denúncias de abuso policial e pela atuação de movimentos sociais que colocaram a dimensão civil dos direitos humanos na ordem do dia (Caldeira, 1991; Adorno, 1998) ${ }^{1}$. Esse contexto político repercutiu na produção acadêmica sobre segurança pública, que dedicou e continua dedicando parte importante dos seus esforços ao entendimento das dificuldades relativas ao respeito e à valorização dos direitos humanos pelas forças policiais brasileiras (Pinheiro; Sader, 1985; Pinheiro, 1991a, 1991b; Kant de Lima, 1990; 2003; Pinheiro et al., 1999; Mesquita, 1999; Tavares dos Santos, 1997; Caldeira, 2003; Oliveira et al. 2001; Machado; Noronha, 2002; Cano, 2003; Ribeiro; Silva, 2010; Balestreri, 2004; Figueiredo et al., 2013, dentre outros).

Dentre as explicações existentes sobre as dificuldades de incorporação dos princípios de direitos humanos às atividades policiais, destacam-se as que dão peso aos fatores institucionais e à cultura política brasileira. Para Caldeira (2003, p. 136), por exemplo, a violência policial e a deslegitimação dos direitos civis em nosso país estariam associadas à ausência de mecanismos de controle democrático sobre a polícia e à

\footnotetext{
${ }^{1}$ Não existe um entendimento conceitual estabilizado sobre o que são os direitos humanos. Como observou Caldeira (2003, p. 345), "o significado dos direitos humanos depende de como o conceito é articulado politicamente em contextos específicos". Mas tanto os pesquisadores que estudam tais direitos quanto os atores políticos e sociais que atuam em sua defesa reconhecem o seu conteúdo a partir da divisão clássica entre direitos civis e políticos, de um lado, e direitos econômicos, sociais e culturais, de outro (ver Possas et al., 2012). Apesar da discussão desse texto se referir basicamente aos direitos civis (direito à vida, à integridade física, circulação, expressão, opinião e associação), optamos pelo uso do termo mais amplo "direitos humanos", que é predominante no debate público e acadêmico na área de segurança pública.
} 
existência de um "padrão cultural muito difundido e incontestado que identifica a ordem e a autoridade ao uso da violência". A cultura política nacional também é um elemento fundamental nas explicações de Pinheiro (1991a), que sustenta que a persistência das violações de direitos humanos cometidas por agentes estatais estaria relacionada à existência de um "autoritarismo socialmente implantado" que valoriza a violência como forma de resolução de conflitos e que permeia a atuação das instituições da ordem. Se essas explicações têm o mérito de chamar a atenção para a influência do contexto social e político sobre as visões e o comportamento dos policiais em relação aos direitos humanos, elas pecam ao subestimarem o ambiente organizacional e ocupacional na qual as atividades de policiamento ocorrem. É nesse ambiente que é gerada a cultura policial, isto é, o conjunto de valores, crenças e regras informais que orientam o modo como os policiais enxergam o mundo social e o modo como deveriam agir nele. Nesse sentido, a resistência dos policiais aos direitos humanos guardaria relação não apenas com o contexto político e cultural mais amplo da sociedade brasileira, mas também com as especificidades de uma cultura ocupacional que pode ser encontrada em forças policiais de diversas partes do mundo.

São poucos os trabalhos brasileiros que se dedicaram à análise empírica da cultura policial para entender o modo como os policiais veem a realidade e agem nela (Paixão, 1982; Lima, 1995; Bretas; Pancioni, 1999; Muniz, 1999; Beato et al., 2008). Além de minoritários dentro da bibliografia nacional, esses trabalhos são em sua grande maioria formados por estudos qualitativos que apresentam dificuldades para captar variações sistemáticas nas diversas dimensões da cultura policial, dentre as quais a que concebe os princípios de direitos humanos como um empecilho às atividades de policiamento. Por meio de um estudo de survey com os policiais militares do Estado do Paraná, esse trabalho busca contribuir para 
o preenchimento dessas lacunas. Como os policiais militares paranaenses veem os direitos humanos? Eles compartilham visões homogêneas acerca dos direitos humanos ou há visões distintas dentro da corporação? O artigo procura responder essas questões e testar três hipóteses derivadas das teorizações sobre cultura policial: (1) a de que os policiais militares paranaenses partilham visões mais desfavoráveis do que favoráveis aos direitos humanos; (2) a de que os policiais mais velhos são mais resistentes à noção de direitos humanos do que os policiais mais novos; e (3) a de que os policiais que trabalham no nível da rua compartilham uma subcultura ocupacional mais avessa aos princípios de direitos humanos do que os policiais que atuam em atividades administrativas.

Embora o foco deste artigo não seja o comportamento e sim as atitudes dos policiais, parte-se da ideia de que as orientações subjetivas dos policiais militares acerca dos direitos humanos tendem a ter implicações sobre suas práticas diárias de policiamento (Muir, 1977; Herbert, 1998; Terrilet al., 2003). Isso ocorre porque a atividade policial é marcada por um elevado grau de discricionariedade. Como notou Wilson (1968, p. 7), esta característica está presente em varias organizações públicas, mas a polícia se destaca porque nela a discricionariedade aumenta à medida que se desce na hierarquia. O resultado é que os policiais na linha de frente devem fazer cumprir todas as leis e em todas as circunstâncias, mas na prática cabe a eles decidirem onde e como agir. Nesse contexto, a cultura policial influencia os parâmetros para essa ação discricionária, podendo levar ao que Skolnick (2011 [1966]) chamou de "justiça sem julgamento". Assim, acreditamos que estudar o modo como os policiais interpretam os direitos humanos é uma forma de contribuir para o entendimento do próprio padrão de atuação das forças policiais brasileiras. 
Sociologias, Porto Alegre, ano 18, no 41, jan/abr 2016, p. 320-353

\section{Cultura Policial e Direitos Humanos}

A cultura policial é um tema central no campo dos estudos sobre policiamento. A maior parte da bibliografia acadêmica sobre o tema é composta por estudos de origem anglo-saxã (Skolnick, 2011; 2008; Reuss-lanni, 1983; Jermier et al., 1991; Britz, 1997; Chan, 1997; Paoline III, 2003; Manning, 2007; O’Neill et al., 2007; Terril et al., 2003; Herbert, 1998; Reiner, 2004; Micucci; Gomme, 2005; Westmarland, 2008). A referência incontornável é o trabalho clássico de Jerome Skolnick (2011 [1966]), Justice Without Trial, publicado pela primeira vez em 1966. A preocupação fundamental que move essa obra é o entendimento das condições sob as quais a polícia se desvia do império da lei. A explicação proposta por Skolnick parte da ideia de que nas sociedades democráticas há valores conflitantes que corroem a capacidade da polícia obedecer ao império da lei. De um lado, existe a expectativa de que os policiais tenham iniciativa e sejam eficientes na imposição de valores morais implicados na ideia de ordem, mas por outro espera-se que eles ajam estritamente de acordo com regras formais que visam conter suas ações dentro de determinados limites. Como o entendimento desse conflito requer o estudo das diferentes concepções de ordem e legalidade partilhada pelos policiais, Skolnick (2011) voltou-se para o que chamou de "personalidade de trabalho" do policial. Apesar do uso do termo personalidade, o foco da discussão de Skolnick (2011) não é um fenômeno psicológico individual e sim uma cultura socialmente gerada que predisporia os policiais a perceberem o mundo social e a agirem nele de determinada maneira. Essa cultura seria uma resposta cognitiva e comportamental a três elementos característicos do ambiente de trabalho do policial: o perigo, a autoridade e as pressões por eficiência.

Segundo Skolnick (2011), a exposição ao perigo e a necessidade de fazer valer a autoridade do Estado estimularia nos policiais atitudes con- 
servadoras e comportamentos de suspeição, estereotipação, isolamento social e solidariedade interna. Policiais desenvolveriam atitudes de suspeição e criariam estereótipos sociais para lidar com as incertezas inerentes aos encontros cotidianos com pessoas desconhecidas. Já o isolamento social seria uma forma de os policiais evitarem o contato com segmentos sociais considerados perigosos e que os tratam com hostilidade em função da autoridade que exercem para garantir o cumprimento da lei. A hostilidade contra os policiais e o isolamento social, por sua vez, levariam ao desenvolvimento de uma forte solidariedade interna. Como autoridade responsável pela manutenção da ordem, os policiais também tenderiam a desenvolver um conservadorismo intelectual (pragmatismo), político e social. Como notou Skolnick (2011), acreditar e defender a ordem e o sistema legal para o qual se busca garantir obediência é fundamental para que os policiais não vivam em permanente conflito cognitivo.

Além de terem de lidar com as consequências do perigo e da autoridade, Skolnick (2011) sustenta que os policiais também precisam desenvolver respostas que os auxiliem a se ajustar e a superar pressões para que pareçam eficientes. A desvalorização das normas que protegem os direitos humanos contra o arbítrio policial seria um desses ajustes. Segundo Skolnick (2011), as pressões por eficiência induziriam os policiais a valorizarem mais a resolução de crimes e a realização de prisões do que o respeito às regras que visam impor limites ao desempenho dessas funções. Todavia, para autores como Reiner (2004), as pressões por resultados que podem levar à desvalorização dos princípios legalistas do devido processo legal não são apenas externas aos policiais. Elas se originariam também de uma força motivadora interna, isto é, do modo como os policiais encaram o seu trabalho, visto como uma missão que se destina a proteger os fracos da ação dos predadores. Assim, essa visão moralista do mandato policial e as pressões organizações por resultados levariam 
os policiais a terem pouco apreço pelas normas que visam proteger os direitos humanos, percebidas como um empecilho ao combate eficiente daqueles que oprimem e brutalizam a sociedade. Nas palavras de um entrevistado de Reiner (2004, p. 139), "falando do ponto de vista de um policial, não se dá a mínima se oprimimos quem rompe a lei, porque, ao modo deles, eles são opressores".

Embora Skolnick (2011) reconheça que a intensidade das características da personalidade de trabalho do policial possa variar, ele ressalta que há bases organizacionais sólidas para sustentar a generalidade dessa personalidade. Isso porque os policiais passariam pelo mesmo processo de recrutamento e iniciariam a carreira realizando atividades de patrulhamento. Essa entrada única na carreira garantiria uma socialização comum na qual os policiais mais velhos ensinariam aos mais novos como executar o policiamento e lidar com o perigo, a autoridade e as pressões por eficiência. A consequência disso seria a formação de uma personalidade de trabalho que tenderia a estar presente nos mais variados contextos nacionais.

Essa pretensa generalidade da cultura policial foi uma das razões pela qual a explicação de Skolnick (2011) tornou-se o paradigma dominante da bibliografia sobre cultura policial, inspirando trabalhos realizados em forças policiais de diversas partes do mundo. Mas esse paradigma não está isento de críticas. A mais dura partiu de um autor de fora da tradição anglo-saxã de estudos sobre policiamento, Dominique Monjardet (2003), que acusou o paradigma hegemônico de ser etnocêntrico e determinista. Etnocêntrico porque tomou o recrutamento comum e a iniciação na carreira em atividades de patrulhamento, comuns no mundo anglo saxão, como algo universal. E determinista porque estabeleceu uma relação mecânica entre condições de trabalho e propriedades cognitivas que ignora o fato de o perigo, a autoridade e as pressões por eficiência presentes no trabalho policial não serem situações objetivas e sim inter- 
pretadas a partir das expectativas que os policiais têm a respeito do ofício que escolheram exercer. Segundo Monjardet (2003), as distintas formas de recrutamento, a diversidade de missões e expectativas em torno do trabalho de policiamento dariam ensejo a uma cultura ocupacional plural e heterogênea ao invés de monolítica. Essa pluralidade pôde ser notada, por exemplo, na distinção proposta por Reuss-Ianni e lanni (1983) entre a cultura dos policiais administrativos (management cop culture) e a cultura dos policiais de rua (street cop culture). Essa crítica é em grande medida partilhada por Reiner (2004), que considera que o trabalho de Skolnick (2011) deu pouca importância para o ambiente político e social no qual a cultura policial é gerada e para as variações que podem ocorrer nessa cultura dentro e entre forças policiais. Essas críticas também foram endossadas por Chan (1997) e Sklansky (2007), Manning (2007) e Cockcroft (2007), que acrescentaram que a ideia de uma cultura policial homogênea, poderosa, determinista e isolada do ambiente externo também deve ser questionada porque deixa pouco espaço para a mudança cultural.

Apesar de decisivas, nenhuma dessas críticas nega a pertinência da noção de cultura policial. Em linhas gerais, a bibliografia acadêmica concorda com a ideia de que os valores, as atitudes e as regras informais que orientam os policiais não podem ser reduzidas às subjetividades e individualidades policiais. Como notou Reiner (2004), as forças policiais das democracias liberais modernas "veem-se frente a frente com as mesmas pressões básicas similares que modelam uma cultura distinta e característica em muitas partes do mundo, mesmo tendo ênfases diferentes no tempo e no espaço, e variações subculturais internas" (Reiner, 2004, p. 132). Nesse sentido, a desvalorização das proteções aos direitos humanos e as demais características da cultura policial precisam ser interpretadas à luz de uma perspectiva analítica sensível tanto ao contexto político e social no qual as atividades de policiamento se desenvolvem, quanto às 
variações e mudanças que podem ocorrer na cultura policial dentro e entre organizações.

Essa perspectiva analítica tem se realizado de forma problemática na restrita bibliografia brasileira que tratou do tema. Os trabalhos empíricos mais importantes sobre a cultura policial no Brasil são estudos de caso que analisaram ou a Polícia Civil ou a Polícia Militar dos Estados de Minhas Gerais e Rio de Janeiro (Paixão, 1982; Lima, 1995; Bretas; Pancioni, 1999; Muniz, 1999; Beato et al., 2008). A desvalorização dos direitos humanos e vários outros elementos apontados pela teoria como partes da cultura policial foram identificados nos estudos brasileiros, mas pouco sabemos sobre como esses elementos variam dentro das forças policiais e entre elas. Não há na bibliografia nacional estudos comparativos entre organizações policiais e são escassos os estudos quantitativos que buscam captar variações sistemáticas nas dimensões da cultura policial de uma mesma organização.

O trabalho brasileiro pioneiro no estudo da cultura policial é a pesquisa qualitativa de Paixão (1982) sobre a Polícia Civil da Região Metropolitana de Belo Horizonte. Nesse estudo, o autor descobriu que os policiais da linha de frente não se orientam primariamente pela lei e sim por um estoque de conhecimento informal que comporia a cultura organizacional da polícia. Esse estoque de conhecimento seria formado por teorias sobre a origem e a natureza dos criminosos, métodos próprios de investigação e por uma série de outros conhecimentos aprendidos informalmente e que contrastam fortemente com os valores e comportamentos formalmente prescritos pela organização. Na cultura organizacional dos policiais civis, os instrumentos legais e os princípios de direitos humanos seriam encarados como obstáculos à realização de um policiamento eficiente $^{2}$. A desvalorização dos direitos humanos também pode ser notada

\footnotetext{
${ }^{2}$ Essa visão foi assim expressa por um policial entrevistado por Paixão (1982, p. 74): "não temos amparo legal com que enfrenta-los (os fora-da-lei) sem sérios riscos, ao passo que eles nos enfrentam com a lei da bala e da peixeira, sob o pálio dos direitos humanos".
} 
no estudo de Paixão (1982) na auto-definição dos policiais como "lixeiros da sociedade", que implica na visão moralista, segundo qual a clientela da polícia não é formada por cidadãos portadores de direitos fundamentais e sim pelo resíduo marginal, pela escória que precisa ser separada da sociedade e reciclada. Descobertas semelhantes também foram encontradas nas pesquisas qualitativas de Lima (1995) e Bretas e Pancioni (1999) sobre a polícia civil do Rio de Janeiro. Bretas e Pancioni (1999) descreveram a cultura dos policiais civis analisados como sendo marcada pelo isolamento social, pelo conservadorismo, pela desconfiança e pela visão segundo qual os direitos humanos impedem os policiais de exercerem sua função e fazerem valer a sua autoridade. Segundo os autores, essa visão era particularmente forte entre os policiais mais velhos, que associavam a defesa dos direitos humanos ao processo de democratização, mas também era reproduzida de forma quase mecânica por policiais mais jovens. Todavia, como essa constatação está baseada em um restrito número de entrevistas em profundidade, não é possível saber ao certo se essas variações eram particulares aos policiais entrevistados ou se conformavam um padrão mais amplo e válido para toda a Polícia Civil do Estado do Rio de Janeiro.

A despeito das limitações dos estudos mencionados acima, eles foram usados para sustentar explicações mais gerais sobre as relações tensas entre polícia e direitos humanos no Brasil (Adorno, 1998; Ratton, 2007; Sapori; Barnabé de Souza, 2001; Sapori, 2007). Ratton (2007) e Sapori (2007), por exemplo, combinaram o trabalho de Paixão (1982) e Skolnick (2011) para argumentar que a violência policial no Brasil pode ser explicada sem referência às particularidades da sociedade brasileira ou à existência de uma organização policial de caráter militar. Segundo os autores, a violência policial transcende as fronteiras nacionais e é praticada tanto por policiais civis quanto por policiais militares. A explicação para esse fenômeno estaria na cultura policial, ou seja, na existência de um estoque 
de conhecimento informal dentro da polícia civil e da polícia militar que desvaloriza as regras do devido processo legal e os direitos humanos.

Embora seja teoricamente problemático explicar a violência policial unicamente em função da existência de uma cultura policial que desvaloriza os direitos humanos, as mais destacadas pesquisas empíricas existentes no Brasil sobre a Polícia Militar também apontam para a existência de uma cultura com essas características (Muniz, 1997; Beato et al., 2008). Ao estudar a Polícia Militar do Estado do Rio de Janeiro, Muniz (1997) descobriu que essa organização era atravessada por uma cultura institucional que valorizava o senso de missão, a hierarquia e a disciplina intrínseca ao modelo militar, e por uma cultura das ruas cujos traços mais marcantes eram o isolamento, a solidariedade interna, a suspeição, a estereotipação, o cinismo, o pragmatismo, o machismo e a valorização da ação, da juventude e da virilidade. Muniz pôde constatar que os policiais das ruas corriqueiramente associavam cidadania e direitos humanos de forma nebulosa, indefinida e até mesmo prejudicial a eles, que julgavam terem poucos direitos ao passo que os cidadãos os teriam em demasia (Muniz, 1997; p. 151-2). Segundo a autora, os traços dessa cultura policial variavam de acordo com as características individuais dos policiais e de acordo com a sua posição no interior da organização. Enquanto os valores da cultura institucional eram mais salientes entre os oficiais, os traços da cultura policial das ruas eram mais claros entre os não-oficiais. Mas tais conclusões também são limitadas pela metodologia empregada no estudo, que fez suas inferências com base na observação etnográfica de policiais que trabalhavam em atividades de patrulhamento ostensivo.

Menos problemático na detecção de variações na cultura policial é o estudo de survey realizado por Beato, Rabelo e Oliveira Júnior (2008) na Polícia Militar de Belo Horizonte, que também constatou a existência de valores e atitudes contrárias aos direitos humanos, especialmente entre 
os policiais da linha de frente. Nesse estudo, os autores traçaram o perfil profissional dos policiais militares com o objetivo de descobrir em que medida esse perfil constrangia a substituição do estilo de policiamento tradicional pelo estilo de policiamento orientado para problemas (POP). A análise revelou haver dois perfis: o comunitário, que privilegiava as interações com a comunidade e a resolução de problemas junto às mesmas, e o tradicional, que privilegiava o uso da força. Esses perfis refletiriam em grande medida a cultura organizacional da polícia, que assumiria feições distintas a depender da posição ocupada pelos policiais no interior da organização (oficiais gestores x não-oficiais da linha de frente). A desvalorização dos direitos humanos foi detectada como estando fortemente associada ao perfil tradicional e à cultura dos policiais de rua. Policiais com esse perfil, por exemplo, tinham uma chance $63 \%$ maior do que os outros de considerarem os movimentos de direitos humanos um empecilho às atividades de policiamento.

A revisão acima demonstra haver um razoável consenso na bibliografia internacional e nacional a respeito da existência de uma cultura policial conformada e caracterizada nos termos descritos inicialmente por Skolnick(2011) e complementada posteriormente por vários autores. Há também uma forte concordância quanto ao fato de que a desvalorização dos direitos humanos é um dos traços dessa cultura. As críticas dirigidas ao paradigma skolnickiano são menos no sentido de negar a existência de uma cultura policial singular e mais no sentido de afirmar a existência de variações nessa cultura dentro das forças policiais e entre elas. Essa perspectiva teórica atenta às variações na cultura policial tem comparecido nos estudos brasileiros sobre o tema, mas o predomínio das metodologias qualitativas e dos estudos de caso único tem dificultado análises mais sofisticadas sobre variações culturais dentro das organizações e entre elas. As hipóteses de pesquisa apresentadas e testadas na sequência visam suprimir parcialmente 
essa lacuna por meio de uma pesquisa de survey realizada na Polícia Militar do Estado do Paraná (PMPR) que segue a linha metodológica inaugurada pelo estudo de Beato, Rabelo e Oliveira Júnior (2008), que é o único da bibliografia brasileira a explorar a existência de uma cultura policial com uma metodologia quantitativa capaz de inferir de forma robusta a existência de variações subculturais no interior de uma organização.

\section{Hipóteses}

As hipóteses de pesquisa desse trabalho partem da ideia de que a visão dos policiais acerca dos direitos humanos pode ser estudada como uma das dimensões que compõem a cultura policial. Considerando isso e tendo como ponto de partida a bibliografia explorada na seção anterior, foram formuladas as seguintes hipóteses de pesquisa:

Hipótese 1: os policiais da PMPR partilham visões mais desfavoráveis do que favoráveis aos direitos humanos. Estes seriam vistos pelos policiais mais como um entrave ao combate à criminalidade do que como valores universais positivados em normas e procedimentos que visam proteger todos os cidadãos, especialmente contra o arbítrio estatal. Essa desvalorização seria uma resposta policial tanto às pressões externas para que pareçam eficientes no combate à criminalidade (Skolnick, 2011), quanto às pressões internas geradas por uma ocupação que é encarada como uma cruzada moral que deve proteger os homens de bem da ação dos predadores que estão à margem da sociedade (Reiner, 2004; Paixão, 1982).

Hipótese 2: Os policiais mais velhos da PMPR são mais resistentes à noção de direitos humanos do que os policiais mais jovens. Os valores, as atitudes e as regras informais que orientam os policiais são ensinadas pelos policiais mais velhos aos policiais mais jovens, que 
dessa forma aprendem a lidar com os perigos, com a autoridade e com as pressões por eficiência presentes no seu ambiente ocupacional e organizacional. Sendo a rejeição aos direitos humanos um dos elementos da cultura policial, espera-se que essa rejeição seja mais forte entre os policiais mais velhos e mais integrados à cultura policial do que entre os policiais mais jovens e em processo de integração.

Hipótese 3: os policiais da PMPR que trabalham na linha de frente da organização compartilham uma subcultura ocupacional mais desfavorável à efetivação dos direitos humanos do que os policiais que desempenham atividades gerenciais e administrativas. Essa hipótese está baseada na distinção proposta por Reuss-lanni e lanni (1983) entre a cultura dos policiais administrativos (management cop culture), que valoriza tanto os resultados quanto os meios utilizados no combate à criminalidade, e a cultura dos policiais de rua (street cop culture), que valoriza mais os resultados do que os meios. Segundo esses autores, essas divisões são esperadas em organizações cuja autoridade e responsabilidade são dispersas e que sofrem pressões políticas e sociais constantes para a alteração de procedimentos e operações. Esse é o caso das polícias militares brasileiras em geral, que desde a redemocratização têm sido alvo de críticas de diversos setores da sociedade por violações de direitos humanos, e cujo organograma é dividido entre oficiais responsáveis pela direção da organização (tenentes, capitães, majores, tenentes-coronéis e coronéis) e não-oficiais que executam as atividades de patrulhamento nas ruas $^{3}$ (soldados, cabos, sargentos e subtenentes). Nessas condições, pode se prever que as visões desfavoráveis aos direitos humanos serão mais intensas entre os policiais operacionais, que estariam mais

${ }^{3} \mathrm{O}$ organograma da PMPR ainda inclui os cadetes, alunos oficiais do $1^{\circ}, 2^{\circ}$ e $3^{\circ}$ ano do Centro de Formação de Oficiais (CFO), e os aspirantes a oficiais, que são os recém formados no CFO que ainda estão em estágio probatório. 
Sociologias, Porto Alegre, ano 18, no 41, jan/abr 2016, p. 320-353

preocupados em combater o crime do que em respeitar as regras que visam proteger os direitos humanos, do que entre os policiais em posição de gestão, que precisam se comprometer com a legalidade do trabalho policial e valorizar as políticas e procedimentos formais da organização.

\section{Metodologia}

Os dados analisados na próxima seção são provenientes da pesquisa "Direitos Humanos, Igualdade de Gênero e Ação Policial da Polícia Militar do Paraná". O objetivo da pesquisa foi captar as orientações subjetivas dos policiais militares paranaenses sobre direitos humanos e gênero. Para isso, foi realizado um survey com os policiais militares da ativa, que no momento da confecção do plano amostral (março de 2012) compunham um efetivo de 16.267 indivíduos. Considerando um erro amostral de 4\% e um nível de confiança de 95\%, foi sorteada uma amostra com 600 indivíduos por meio da técnica de conglomerado em dois estágios: no primeiro foram selecionadas as unidades administrativas de policiamento e no segundo os policiais.

O instrumento utilizado para a coleta dos dados foi um questionário autoaplicável, composto por setenta e quatro questões. Na parte relativa aos direitos humanos, as perguntas foram divididas em três blocos: 1) "Conteúdo dos Direitos Humanos"; 2) "Adesão aos Direitos Humanos"; e 3) "Disposições a respeito da violência policial". Os dados analisados na próxima seção são originários de perguntas do segundo bloco do questionário, ou seja, perguntas realizadas com o objetivo de mensurar, com escalas de Likert de quatro pontos, os valores e as atitudes dos policiais em relação à noção de direitos humanos. 
Essas perguntas foram submetidas à análise estatística descritiva e, posteriormente, a uma análise fatorial implementada com o objetivo de construir um Índice de Rejeição aos Direitos Humanos (IRDH). A análise estatística descritiva das perguntas que compuseram o índice e do próprio IRDH permitiram avaliar a primeira hipótese do trabalho. Para testar as demais hipóteses, utilizou-se a técnica estatística da Análise de Variância (ANOVA).

\section{Resultados}

As respostas às questões referentes à disposição dos membros da PMPR sobre a relação entre atividade policial e direitos humanos podem ser vistas na tabela 1, que apresenta o grau de concordância (em percentual) dos entrevistados em relação a cinco afirmações sobre o tema. 
Sociologias, Porto Alegre, ano 18, no 41, jan/abr 2016, p. 320-353

Tabela 1. Relações entre atividade policial e direitos humanos (\%)

\begin{tabular}{|c|c|c|c|c|}
\hline & $\begin{array}{l}\text { Discorda } \\
\text { Muito }\end{array}$ & Discorda & Concorda & $\begin{array}{c}\text { Concorda } \\
\text { Muito }\end{array}$ \\
\hline $\begin{array}{l}\text { A abordagem policial não é } \\
\text { eficiente quando observa } \\
\text { todos os princípios teóricos } \\
\text { dos direitos humanos. }\end{array}$ & 25,6 & 18,0 & 30,5 & 25,9 \\
\hline $\begin{array}{l}\text { As normas de direitos } \\
\text { humanos prejudicam } \\
\text { a aplicação da lei penal. }\end{array}$ & 21,0 & 12,3 & 33,3 & 33,3 \\
\hline $\begin{array}{l}\text { Os direitos humanos são um } \\
\text { obstáculo na luta contra a } \\
\text { violência criminal. }\end{array}$ & 17,9 & 14,7 & 33,2 & 34,2 \\
\hline $\begin{array}{l}\text { Os bandidos usam os direitos } \\
\text { humanos para se esquivarem } \\
\text { da aplicação da lei penal. }\end{array}$ & 08,7 & 06,4 & 24,8 & 60,1 \\
\hline $\begin{array}{l}\text { Os direitos humanos protegem } \\
\text { os bandidos. }\end{array}$ & 08,2 & 07,2 & 31,3 & 53,3 \\
\hline
\end{tabular}

Nota: $\mathrm{N}=629$ para todas as variáveis.

Fonte: Direitos Humanos, Igualdade de Gênero e Ação Policial da Polícia Militar do Paraná.

Como é possível notar, os policiais apresentam disposições predominantemente desfavoráveis aos direitos humanos. "Concorda" e "concorda muito" concentram as respostas em todas as perguntas, chegando a mais de $80 \%$ das respostas no caso das duas últimas afirmações. Mesmo no caso da afirmação sobre eficiência do trabalho policial, que obteve o menor percentual somatório, verifica-se mais de 55 pontos nas opções "concorda" e "concorda muito". Assim, confirma-se a hipótese de que a 
cultura dos policiais da PMPR é dominada por visões mais desfavoráveis do que favoráveis aos direitos humanos.

Como apontamos na seção anterior, para prosseguir no teste das demais hipóteses optamos por um procedimento de redução dos dados em um índice que pudesse, de maneira parcimoniosa, mas sem perda significativa de informação, representar adequadamente o conjunto das questões. Como todas as variáveis são medidas no nível discreto por meio de escalas de Likert de quatro pontos (do discorda muito ao concorda muito), não foi possível utilizar a técnica de análise fatorial tradicional, já que a mesma se vale da matriz de correlação de Pearson, válida apenas para variáveis contínuas (Gorsuch, 1983). Desta forma, foi necessário recorrer à análise fatorial baseada em uma matriz de correlação policórica (Drasgow, 1988). A análise efetuada a partir desse procedimento (Tabela 2) indicou a pertinência da redução, uma vez que as cinco variáveis carregaram adequadamente no único fator gerado e o conjunto da análise apresentou nível de significância aceitável $(0,000)$. Como os resultados descritos anteriormente já haviam apontado, a pergunta referente à eficiência policial é a que apresenta a menor carga $(0,524)$, mas ainda assim superior ao que a literatura aponta como valor crítico (Drasgow, 1988). 
Sociologias, Porto Alegre, ano 18, no 41, jan/abr 2016, p. 320-353

Tabela 2. Análise fatorial policórica

Relação entre Direitos Humanos e atividade policial

Carga

Fatorial

A abordagem policial não é eficiente quando observa todos os princípios teóricos dos direitos humanos.

As normas de direitos humanos prejudicam a aplicação da lei penal.

Os direitos humanos são um obstáculo na luta contra a violência criminal.

Os bandidos usam os direitos humanos para se esquivarem da aplicação da lei penal.

Os direitos humanos protegem os bandidos.

Notas: Análise Fatorial com método de Fatores Principais a partir de Matriz de Correlação Policórica com um único fator e sem rotação. Fator 1 com Eigenvalue 2.560.

Teste LR: Independente Vs. Saturado (qui-quadrado)=1253,20, sig. =0,000.

Fonte: Direitos Humanos, Igualdade de Gênero e Ação Policial da Polícia Militar do Paraná.

Com base nesses resultados construímos o Índice de Rejeição aos Direitos Humanos (IRDH) a partir da somatória das cinco questões apresentadas anteriormente. A medida pode variar de 0 (pessoas que "discordam muito" de todas as questões) a 15 (pessoas que "concordam muito" com todas as questões). Como mostra o gráfico 1, a distribuição dessa medida revela concentração nos valores mais elevados, demonstrando uma vez mais que predomina entre os policiais militares do Paraná sentimentos e atitudes de rejeição aos direitos humanos em suas atividades profissionais ${ }^{4}$.

\footnotetext{
${ }^{4}$ Apesar dessa distribuição o teste de inclinação retornou o valor de -,603, dentro dos padrões de normalidade exigidos pela literatura para a inclusão da medida como variável dependente em testes estatísticos multivariados.
} 


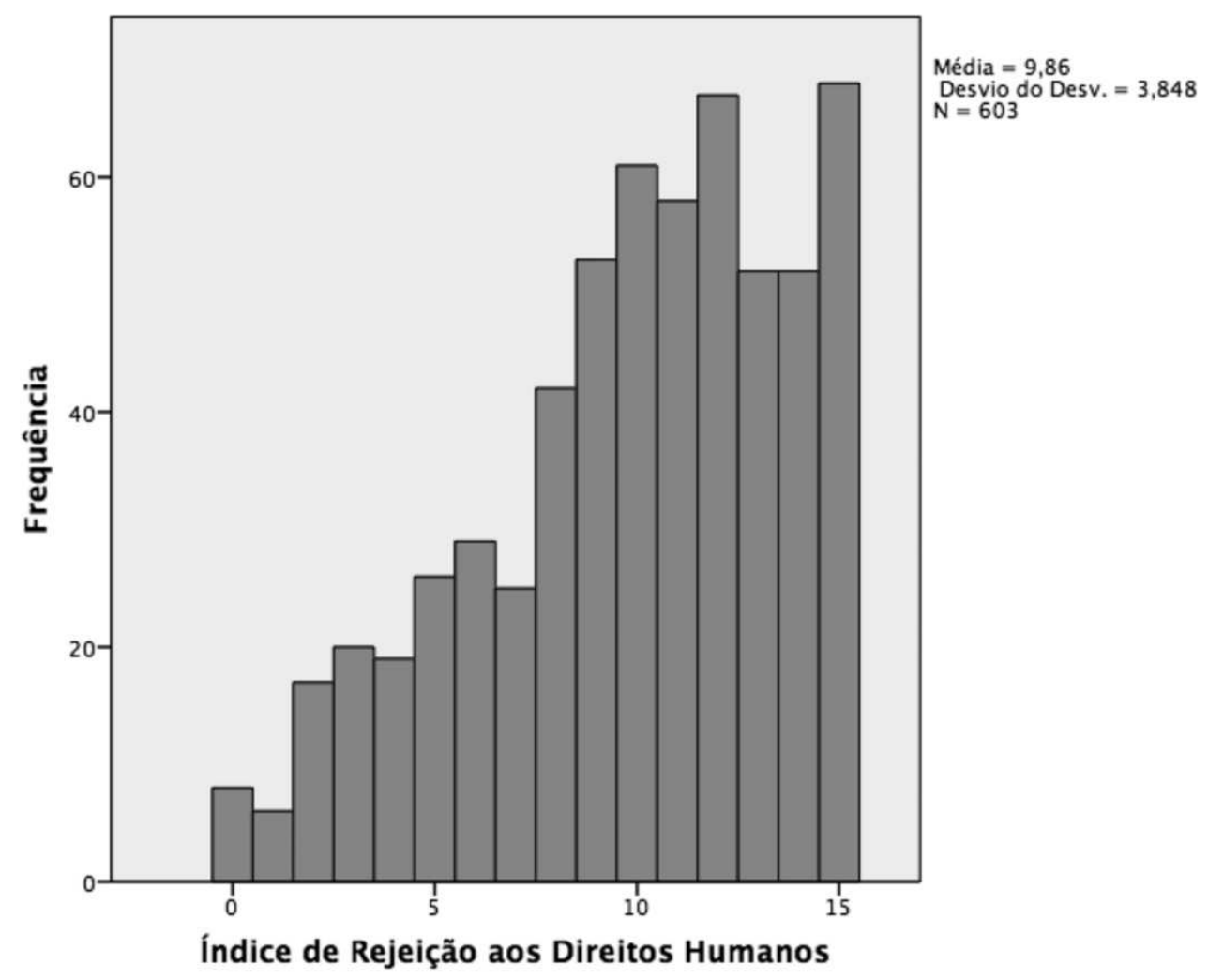

Gráfico 1. Índice de Rejeição aos Direitos Humanos

O IRDH foi então utilizado para testar as hipóteses que relacionam o grau de rejeição aos direitos humanos com a idade e a função desempenhada pelos policiais. Para analisar se os policiais mais velhos e integrados à cultura policial são mais resistentes aos direitos humanos do que os policiais mais novos e com menos tempo de integração, realizamos um teste Anova Unidirecional ${ }^{5}$ envolvendo o IRDH e a idade recodificada em três faixas (1=de 18 à 28 anos, $2=$ de 29 à 35, 3=mais de 35). Esses grupos etários foram estabelecidos em razão da idade média de entrada dos recrutas nas duas últimas seleções de soldados para a PMPR (26 anos). A faixa mais

${ }^{5}$ Como os modelos Anova Unidirecionais são sensíveis à presença de outliers, foram excluídos dois casos da amostra que destoavam fortemente do padrão dos casos. No que diz respeito à exigência da homogeneidade na distribuição do IRDH entre os grupos etários a estatística de Levene de 2,791, com nível de significância de 0,062 para a aceitação da hipótese nula confirma a validade da análise. 
jovem, portanto, envolve indivíduos que tem pouco tempo de serviço na corporação, logo, pouca exposição à cultura policial. O segundo grupo, por sua vez, reuniria policiais com experiência de socialização moderada. Já o último reuniria os mais experientes e, possivelmente, os que mais assimilaram os valores da cultura policial. Os resultados dessa análise (Gráfico 2 e Tabela 3) confirmam a existência de diferenças nas médias de pontuação no IRDH entre os grupos etários, entretanto, não no sentido esperado. No Gráfico 2 é possível perceber redução nas médias do IRDH representadas por cada uma das colunas relativas aos grupos etários, sendo justamente menor a dos mais experientes, mesmo se considerarmos os erros nas estimativas. Na Tabela 3 observamos que a média para o primeiro grupo é de 10,41, passando para 10,24 no segundo e, por fim, 9,45 no terceiro. A estatística do teste de 3,984 com nível de significância de ,019 indica claramente que essas diferenças são estatisticamente significativas. 
Sociologias, Porto Alegre, ano 18, no 41, jan/abr 2016, p. 320-353

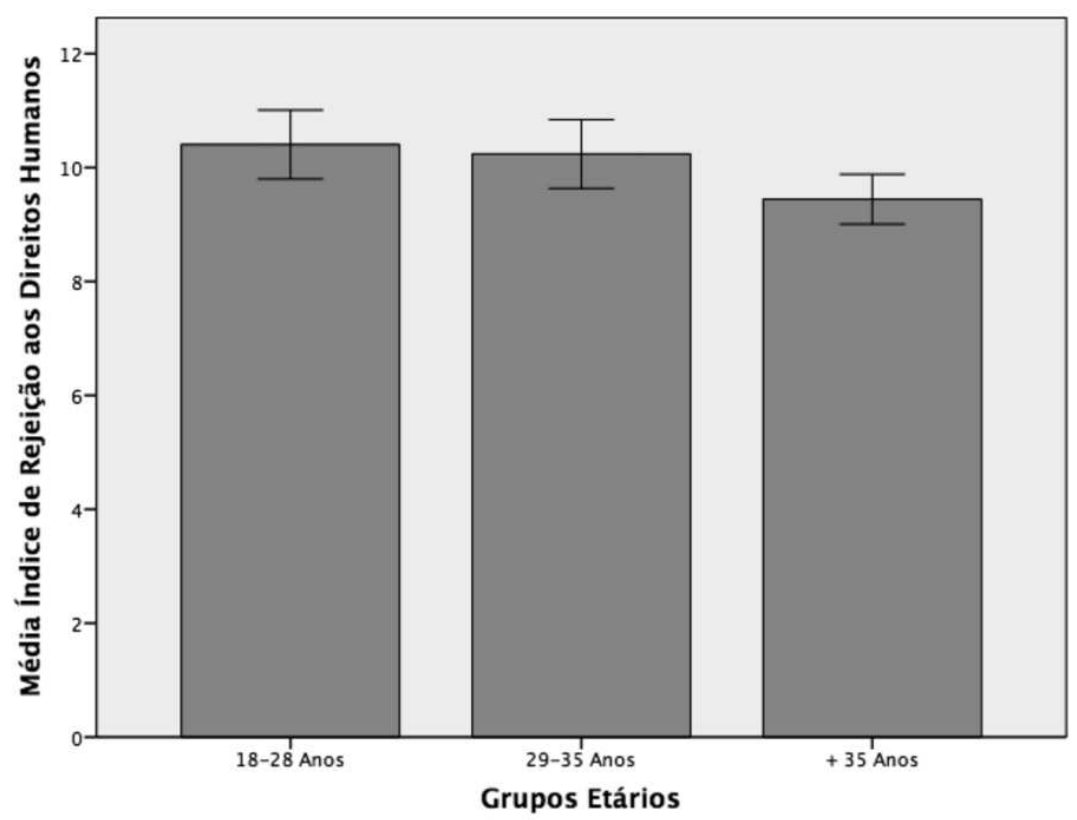

Gráfico 2. Médias no IRDH por grupo etário.

Tabela 3. Teste Anova para IRDH entre Grupos Etários

\begin{tabular}{lcccc}
\hline & Média & $\begin{array}{c}\text { IRDH } \\
\text { Desvio- }\end{array}$ & $\begin{array}{c}\text { Erro- } \\
\text { Padrão }\end{array}$ & $N^{\circ}$ de casos \\
\cline { 2 - 5 } & 10,41 & 3,59 &, 306 & 138 \\
$29-35$ & 10,24 & 3,53 &, 305 & 134 \\
+35 & 9,45 & 4,03 &, 222 & 328 \\
Total & 9,84 & 3,84 &, 157 & 600 \\
Estatística do teste & 3,984 sig. $=0,019$ & & & \\
\hline
\end{tabular}

Fonte: Direitos Humanos, Igualdade de Gênero e Ação Policial da Polícia Militar do Paraná. 
Para testar nossa terceira hipótese, acerca da relação entre a atividade policial operacional e maior rejeição aos direitos humanos, adotamos esses mesmos procedimentos, substituindo agora a idade por uma medida dicotômica que distingue os policiais em dois grupos em razão das funções que desempenhavam no momento da coleta dos dados: administrativos e operacionais ${ }^{6}$. O Gráfico 3 mostra claramente que entre o grupo dos que exerciam atividade operacional a média do IDRH é maior, mesmo considerando o erro padrão da estimativa. A Tabela 4 revela diferença de mais de um ponto na média e o valor do teste de 5,540 e nível de significância de ,019 indicam a consistência dessa diferença. Desta vez, como esperado, os resultados indicam que aqueles envolvidos nas atividades fins da PMPR são os que apresentam maior resistência aos princípios de direitos humanos.

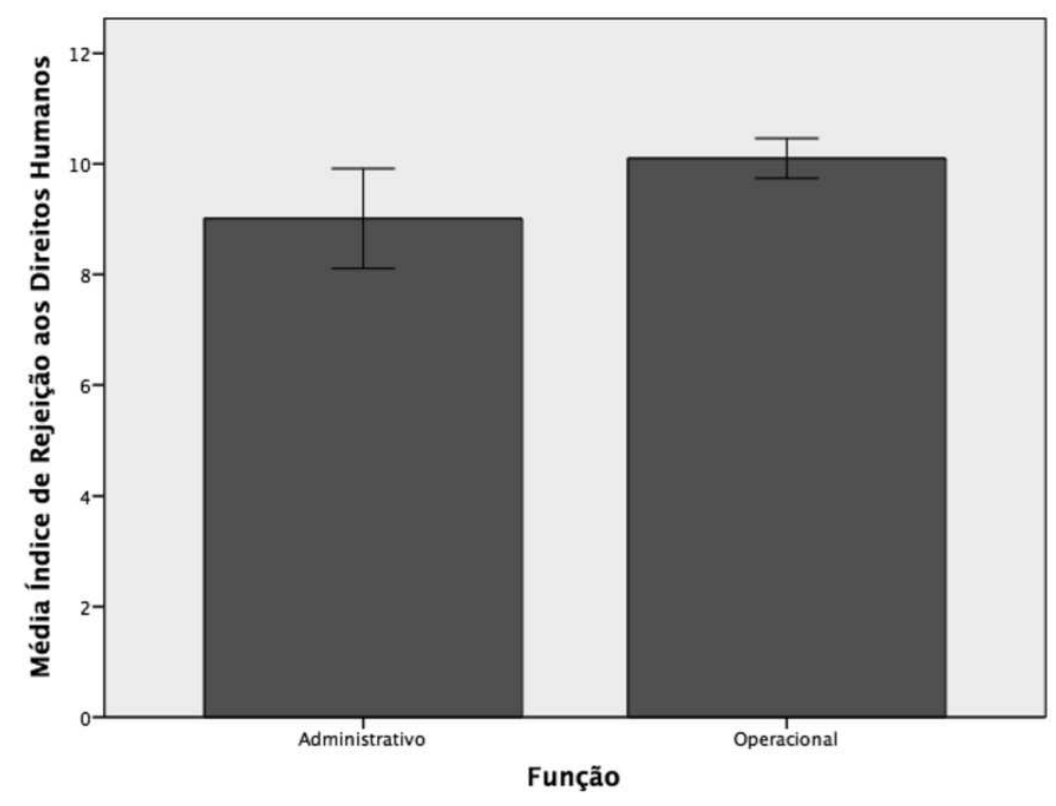

Gráfico 3. Médias no IRDH por função.

\footnotetext{
${ }^{6}$ Um problema na coleta dos dados gerou 120 respostas ausentes na questão sobre atividade operacional ou administrativa. Esse erro, entretanto, se distribuiu de forma aleatória sobre a amostra, desta forma, consideramos que a representatividade continue sendo satisfatória, apesar da ampliação da margem de erro.
} 
Tabela 4. Teste Anova para IRDH entre Administrativos e Operacionais

\begin{tabular}{lcccc}
\hline & \multicolumn{4}{c}{ IRDH } \\
\cline { 2 - 5 } & Média & $\begin{array}{c}\text { Desvio- } \\
\text { Padrão }\end{array}$ & $\begin{array}{c}\text { Erro- } \\
\text {-Padrão }\end{array}$ & $N^{\circ}$ de casos \\
\hline Administrativos & 9,01 & 4,008 &, 454 & 78 \\
Operacionais & 10,10 & 3,686 &, 183 & 404 \\
Total & 9,93 & 3,758 &, 171 & 482 \\
Estatística do teste & 5,540 sig. $=0,019$ & & \\
\hline
\end{tabular}

Fonte: Direitos Humanos, Igualdade de Gênero e Ação Policial da Polícia Militar do Paraná.

Uma hipótese secundária derivada da distinção entre "policiais de rua" e "policiais administrativos" sugere também a existência de diferenças de atitudes em relação aos direitos humanos entre não-oficiais e oficiais $^{7}$, já que os primeiros tendem a atuar por mais tempo em atividades operacionais. O Gráfico 4 mostra que o grupo dos não-oficiais apresenta média superior no IRDH, se comparados aos oficiais. A Tabela 5 revela que essa diferença é de quase dois pontos e que a mesma é estatisticamente significativa $(6,008$ e sig. $=, 015)$, ou seja, os não-oficiais rejeitam mais os direitos humanos do que os oficiais, conforme esperado.

\footnotetext{
${ }^{7} \mathrm{O}$ mesmo problema mencionado na nota anterior produziu dados faltantes nas respostas sobre a graduação (se não-oficial
} 
Sociologias, Porto Alegre, ano 18, no 41, jan/abr 2016, p. 320-353

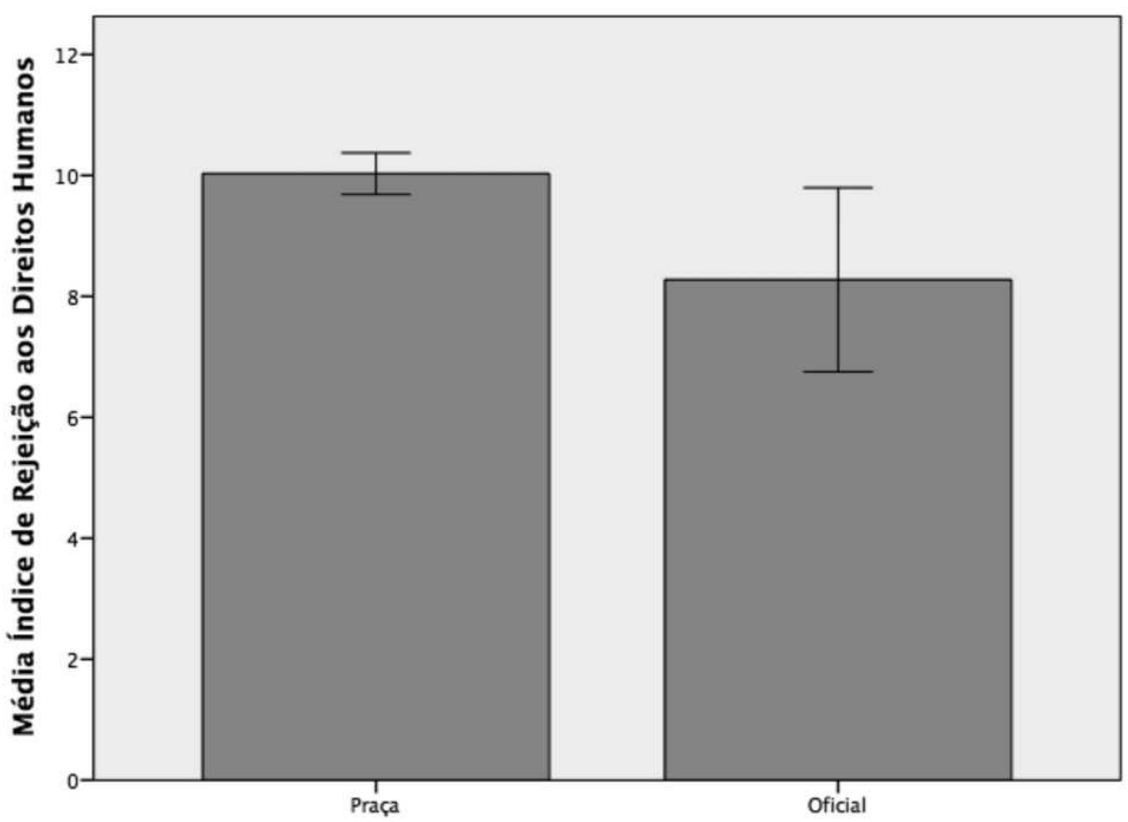

Gráfico 4. Médias no IRDH por graduação (não-oficial e oficial).

Tabela 5. Teste Anova para IRDH entre Administrativos e Operacionais

\begin{tabular}{lcccc}
\hline & \multicolumn{4}{c}{ IRDH } \\
\cline { 2 - 5 } & Média & $\begin{array}{l}\text { Desvio- } \\
\text {-Padrão }\end{array}$ & $\begin{array}{c}\text { Erro- } \\
\text { Padrão }\end{array}$ & $\begin{array}{c}\text { No de }^{\circ} \\
\text { casos }\end{array}$ \\
\hline Não-Oficial & 10,03 & 3,721 &, 175 & 453 \\
Oficial & 8,28 & 3,999 &, 743 & 29 \\
Total & 9,93 & 3,758 &, 171 & 482 \\
Estatística do teste & 6,808 sig. $=0,015$ & & & \\
\hline
\end{tabular}

Fonte: Direitos Humanos, Igualdade de Gênero e Ação Policial da Polícia Militar do Paraná. 


\section{Discussão}

Os resultados expostos anteriormente confirmam claramente a hipótese de que as visões dos policiais da PMPR em relação aos direitos humanos são predominantemente desfavoráveis. Essa realidade é preocupante. Não podemos toma-la como explicação para o abuso policial, pois não existe uma correspondência imediata entre atitudes desfavoráveis aos direitos humanos e violações de tais direitos. Como notou Waddington (1999), existe uma diferença entre o que os policiais dizem e o que eles fazem e há farta evidência de que o comportamento policial é determinado principalmente por variáveis relacionadas ao contexto situacional - tipo de incidente que demanda a ação policial, severidade do crime, existência de prova e suporte legal para agir, grau de visibilidade da ocorrência, número de policiais envolvidos, tipo de relação entre uma eventual vítima e o ofensor, e o comportamento e as características dos suspeitos (Riksheim; Chermak, 1993; Skogan; Frydl, 2004; Sun; Payne; Wu, 2008). Mas causa certa perplexidade saber que funcionários públicos com tamanha discricionariedade e poder veem os direitos humanos como um empecilho ao seu trabalho. Se na maior parte do tempo os policiais agem sem supervisão e orientados apenas por diretrizes genéricas sobre como se comportar, é de se esperar que o modo como veem o mundo social tenha alguma influência sobre suas práticas de policiamento. Ao menos é o que demonstra o estudo de Terril et al. (2003), que encontrou uma associação entre atitudes típicas da cultura policial e o uso de coerção pelos policiais que partilhavam tais atitudes.

A análise estatística realizada anteriormente também confirma a hipótese de que os não-oficiais e os policiais em funções operacionais partilham pontos de vistas mais desfavoráveis aos direitos humanos do que os oficiais e policiais em funções administrativas. Essas descobertas sugerem a existência de subculturas policiais nos termos definidos por 
Reuss-lanni e lanni (1983), ou seja, a existência de uma "subcultura dos policiais de rua", que valoriza fortemente os resultados e por isso concebe os princípios de direitos humanos como um entrave à sua obtenção, e uma "subcultura dos policiais administrativos", mais aderente aos procedimentos legais e, consequentemente, aos princípios de direitos humanos formalmente incorporados pela organização. Essas descobertas também complementam o que sabemos sobre as diferenças entre ranks presentes nas polícias militares do Brasil, que possuem padrões de recrutamento/ seleção, treinamento e carreira diversos para não-oficiais e oficiais. Soares (2008) já demonstrou que essas divisões dão origem a duas proto-instituições que engendram opiniões distintas sobre o papel das demais instituições do Sistema de Justiça Criminal, prestação de contas à sociedade, modelo militar de organização e a importância da hierarquia e da disciplina como mecanismos de controle interno. Nossas descobertas se somam a esses achados ao demonstrar que também há, ao menos na PMPR, diferenças entre oficiais e não oficiais em relação ao nível de rejeição aos direitos humanos. Já a hipótese sobre as variações no grau de rejeição aos direitos humanos em função da idade não se sustenta a partir das evidências coletadas. Com base no entendimento de que a visão dos policiais acerca dos direitos humanos é parte de uma cultura ocupacional transmitida pelos policiais experientes aos policiais mais jovens, esperávamos encontrar níveis de rejeição aos direitos humanos mais intensos entre os policiais experientes e mais integrados à cultura policial. Mas os dados indicam justamente o contrário: é entre os policiais mais jovens e supostamente menos socializados na cultura policial que encontramos as maiores resistências aos direitos humanos. Interessante notar que essa realidade contrasta com os resultados encontrados por Cano (2010), que analisou dados de opinião pública de todo o Brasil referentes à temática direitos humanos, criminalidade e segurança pública e descobriu que os 
mais jovens são os que mais apoiam os direitos humanos, especialmente os que tem entre 25 e 34 anos. Essa situação nos leva a suspeitar que uma explicação possível para os resultados que encontramos é a de que a PMPR atrai indivíduos que partilham visões mais desfavoráveis aos direitos humanos do que as predominantes dentro da corporação e da própria sociedade. Se isso estiver correto, a explicação para o fato de os policiais jovens e com menos tempo de carreira serem os que mais rejeitam os direitos humanos deve ser buscada tanto na cultura política brasileira, que deslegitima os direitos humanos de criminosos, quanto nas próprias características da ocupação policial, que atrairia justamente as pessoas que mais rejeitam os direitos humanos na sociedade brasileira.

\section{Conclusões}

Os estudos sobre polícia e direitos humanos no Brasil têm dado pouca atenção à relação entre cultura policial e visões sobre direitos humanos. Esse tema aparece nos trabalhos brasileiros que estudaram empiricamente a cultura policial, mas a maioria desses trabalhos apresenta dificuldades metodológicas em analisar as variações sistemáticas das dimensões da cultura policial. Esse artigo procurou contribuir para o preenchimento desta lacuna por meio de um estudo de survey focado nas atitudes e visões dos policiais militares do Estado do Paraná acerca dos direitos humanos.

O estudo mostrou que os policiais da PMPR, em geral, compartiIham visões desfavoráveis à efetivação dos princípios de direitos humanos. O estudo também mostrou que a resistência aos direitos humanos é maior entre os não-oficiais e policiais que atuam em funções operacionais do que entre os oficiais e policiais em funções administrativas, indicando a possível existência de uma cultura dos policiais de rua e uma cultura dos policiais administrativos nos termos definidos pela teoria. Todavia, ao con- 
trário do esperado, descobriu-se que a resistência aos direitos humanos é maior entre os policiais mais jovens e com menos tempo de socialização na cultura policial, do que entre os policiais mais velhos e supostamente mais integrados a essa cultura. Esses resultados são intrigantes e merecem pesquisas adicionais, pois podem ter implicações para a formulação e implementação de políticas públicas. O fato de a maior resistência aos direitos humanos localizar-se entre os policiais mais jovens pode ser um indicativo de que a PMPR está recrutando e selecionando pessoas com valores menos aderentes aos princípios de direitos humanos do que os prevalecentes na sociedade e na cultura policial da corporação. Se isso estiver correto, os formuladores de políticas públicas e defensores dos direitos humanos no Brasil devem começar a se preocupar não apenas com a eficácia de cursos e treinamentos em direitos humanos, mas também com os processos de recrutamento e seleção de candidatos para a polícia.

Cleber da Silva Lopes - Doutor em Ciência Política pela Universidade de São Paulo. É Professor Adjunto de Ciência Política do Departamento de Ciências Sociais da Universidade Estadual de Londrina (UEL). $\$ cleber1lopes@hotmail.com

Ednaldo Aparecido Ribeiro - Doutor em Sociologia pela Universidade Federal do Paraná. É Professor Adjunto do Departamento de Ciências Sociais da Universidade Estadual de Maringá. \ednaldorib@yahoo.com.br

Marcos Antonio Tordoro - Mestre em Políticas Públicas pela Universidade Estadual de Maringá. 
Sociologias, Porto Alegre, ano 18, no 41, jan/abr 2016, p. 320-353

\section{Referências}

1. ADORNO, S. Consolidação democrática e políticas de segurança pública no Brasil: rupturas e continuidades. In: ZAVERUCHA, J. (org.). Democracia e instituições políticas brasileiras no final do século XX. Recife: Bagaço, 1998, p. 149-189.

2. BALESTRERI, R.B. Direitos Humanos, segurança pública e promoção da justiça. Passo Fundo: Gráfica Editora Berthier, 2004.

3. BEATO, C.; RABELO, K.; OLIVEIRA JÚNIOR, A. Reforma Policial no Brasil. In: BEATO, C. (org.). Compreendendo e Avaliando: projetos de segurança pública. Belo Horizonte: Editora UFMG, 2008.

4. BRETAS, M.L.; PANCIONI, P. Cultura Policial e o Policial Civil Carioca. In: PANDOLFI et al. (orgs.). Cidadania, justiça e violência. Rio de Janeiro: FGV, 1999. pp. 117-178,

5. BRITZ, M. T. The police subculture and occupational socialization: Exploring individual and demographic characteristics. American Journal of Criminal Justice, 21, 1997. pp. 127-146.

6. CALDEIRA, T.P. Direitos humanos ou 'privilégios de bandidos'? Desventuras da democratização brasileira. Novos Estudos Cebrap, 30:162-174, jul. 1991.

7. CALDEIRA, T.P. Cidade de Muros: crime, segregação e cidadania em São Paulo. 2o ed. São Paulo: Editora 34/Edusp, 2003.

8. CANO, I. Violência Policial. In: CARVALHO, S. (org.). Execuções sumárias no Brasil (1997-2003). Rio de Janeiro: Centro de Justiça Global, 2003.

9. CANO, I. Direitos Humanos, Criminalidade e Segurança Pública. In: VENTURA, G. (org.). Direitos Humanos: Percepções da Opinião Pública: análise de pesquisa nacional. Brasília: Secretaria de Direitos Humanos, 2010, pp. 65-75.

10. CHAN, J. Changing police culture. British Journal of Criminology, 36, 1997. Pp 109- 134.

11. COCKCROFT, T. Police Culture(s): some definitional, methodological and analytical consideration. In: O'NEILL, M.; MARKS, M.; SINGH, A-M. (eds.) Police Occupational culture: new debates and directions. Oxford: Elsevier, 2007.

12. DRASGOW, F. Polychoric and polyserial correlations. In: KOTZ. L., JOHNSON, N.L. (Eds.), Encyclopedia of Statistical Sciences, v. 7. New York: Wiley, 1988. pp. 69-74.

13. FIGUEIREDO, I.; NEME, C.; LIMA, C.S.L. (Org.). Direitos humanos. Brasília: Ministério da Justiça, Secretaria Nacional de Segurança Pública (SENASP), 2013. 382 p. (Coleção Pensando a Segurança Pública; v. 2) 
Sociologias, Porto Alegre, ano 18, no 41, jan/abr 2016, p. 320-353

14. GORSUCH, R.L. Factor analysis (2nd ed.). Hillsdale, NJ: Erlbaum, 1983.

15. JERMIER, J.M. et al. Organizational subcultures in a soft bureaucracy: Resistance behind the myth and facade of an official culture. Organizational Science, 2, 1991. pp. 170-194.

16. KANT DE LIMA, R. Constituição, direitos humanos e processo penal inquisitorial: quem cala, consente? Dados - Revista de Ciências Sociais, Rio de Janeiro, 33, (3), 1990. pp. 47-88.

17. KANT DE LIMA, R. Direitos Civis, Estado de Direito e 'Cultura Policial': A Formação Policial em Questão. Revista Brasileira de Ciências Criminais, ano 11, no 41, 2003. pp. 241-256.

18. MACHADO, E.P.; NORONHA, C.V. A polícia dos pobres: violência policial em classes populares urbanas. Sociologias, Porto Alegre, n. 7, June, 2002. pp. 188-221.

19. MANNING, P. Occupational culture. In: JACK, R.G (Ed.). The Encyclopedia of Police Science. Third Edition. New York: Taylor \& Francis Group, 2007, pp. 865-872.

20. MANNING, P. A Dialectic of Organisational and occupational culture. In: O'NEILL, M.; MARKS, M.; SINGH, A-M. (Eds.) Police Occupational culture: new debates and directions. Oxford: Elsevier, 2007.

21. MESQUITA, P. Violência policial no Brasil: abordagens teóricas e práticas de controle. In: CARVALHO, J.M. et al. (Orgs.) Cidadania, justiça e violência. Rio de Janeiro: Fundação Getúlio Vargas, 1999.

22. MICUCCI, A J.; GOMME, I.M. American police and subcultural support for the use of excessive force. Journal of Criminal Justice, 33, 2005. pp. 487-500.

23. MONJARDET, D. O Que Faz a Polícia. São Paulo: Editora da Universidade de São Paulo, 2003 (Série Polícia e Sociedade, $n^{\circ}$ 10)

24. MUIR, W.K. Police: Streetcorner Politicians. Chicago, III. University of Chicago Press, 1977.

25. MUNIZ, J. Ser policial é, sobretudo, uma razão de ser. Cultura e cotidiano da PMERJ. Rio de Janeiro, 1999. Tese (Doutorado) - Instituto Universitário de Pesquisa do Rio de Janeiro.

26. OlIVEIRA, D.D.; SANTOS, S.A.; SILVA, V.B. (Orgs.) Violência Policial: Tolerância Zero? Goiânia, Editora UFG, 2001.

27. O'NEILL, M.; MARKS, M.; SINGH, A-M. (Eds.) Police Occupational culture: new debates and directions. Oxford: Elsevier, 2007. 
28. PAIXÃO, A.L. A Organização Policial numa Área Metropolitana. Dados - Revista de Ciências Sociais, Rio de Janeiro, vol. 25, no 1, 1982. pp. 63-85.

29. PAOLINE III, E.A. Taking stock: toward a richer understanding of police culture. Journal of Criminal Justice, 31, 2003. pp. 199- 214.

30. PINHEIRO, P.S.; SADER, E. O controle da polícia no processo de transição democrática. Temas IMESC. Soc. Dir. Saúde. São Paulo, 2 (2), 1985. pp. 77-95.

31. PINHEIRO, P. S. Autoritarismo e Transição. Revista da USP, São Paulo, n. 9, 1991a.

32. PINHEIRO, P.S.; IZUMINO, E.A.; FERNANDES, M.C.J. Violência Fatal: conflitos policiais em São Paulo (81-89). Revista USP, São Paulo, 9, mar./mai. 1991b. pp. 95-112.

33. PINHEIRO, P.S.; ADORNO, S.; CARDIA, N. Continuidade autoritária e construção da democracia. Projeto integrado de pesquisa. Relatório Final. São Paulo: NEV/USP, 1999. Disponível em: http://www.nevusp.org/downloads/down000. pdf. Acesso em 13 de nov. de 2014.

34. POSSAS, M. Et al. Monitoramento de violações de direitos humanos e o problema da seleção de direitos: reflexões sobre limites da teoria de direitos humanos. Contemporânea, vol. 2, n. 1, jan-jun. 2012. pp. 103-127.

35. RATTON, J.L. Aspectos Organizacionais e Culturais da Violência Policial. In: RATTON, J.L; BARROS, M. (Orgs.). Polícia, Democracia e Sociedade. Rio de Janeiro: Editora Lumen Juris, 2007, p. 139-151.

36. REINER, R. A Política da Polícia. São Paulo: Editora da Universidade de São Paulo, 2004 (Série Polícia e Sociedade, n 11)

37. REUSS-IANNI, E.; IANNI, F. Street Cops and Management Cops: The two Cultures of Policing. In: PUNCH, M. (org.). Control in the police organization. Cambridge, MA: MIT Press, 1983, p. 251-274

38. RIBEIRO, L.M.L.; SILVA, K.A. As relações entre direitos humanos e práticas dos policiais civis: o papel da percepção dos cidadãos. Revista Debates, Porto Alegre, vol. 4, no 2, jul-dez. 2010. pp. 178-208.

39. RIKSHEIM, E.; CHERMAK, S. Causes of Police Behavior Revisited. Journal of Criminal Justice, v. 21, 1993. pp. 353-382.

40. SKLANSKY, D. A. "Seeing blue: police reform, occupational culture, and cognitive burn-in". In: O'NEILL, M.; MARKS, M.; SINGH, A-M. (eds.) Police Occupational culture: new debates and directions. Oxford: Elsevier, 2007. 
41. SKOLNICK, J. Justice Without Trial: Law Enforcement in Democratic Society. Fourth Edition. New Orleans, Luisiana: Quid Pro Books, 2011 (Classics of Law \& Society Series).

42. SKOGAN, W.; FRYDL, K (Eds.). Fairness and effectiveness in policing: the evidence. Washington, DC: Committee to Review on Police Policy and Practices, 2004.

43. SUN, I.; PAYNE, B.; WU, Y. The impact of situational factors, officer characteristics, and neighborhood context on police behavior: A multilevel analysis. Journal of Criminal Justice, 36, 2008. pp. 22-32

44. TAVARES DOS SANTOS, J. V. A Arma e a Flor: formação da organização polícia consenso e violência. Tempo Social: Revista de Sociologia da USP. 9(1), maio. 1997. pp. 155-167.

45. TERRIL, W.; PAOLINE III, E.; MANNING, P. Criminology, v. 41, n 4, 2003. pp. 1003-1034.

46. WESTMARLAND, L. Police Cultures. In: NEWBURN, T. Handbook of Policing. Second Edition. Portland/Cullompton: Willian Publishing, 2008, pp. 253-280.

47. WILSON, J. Varieties of Police Behavior: The Management of Law and Order in Eight American Communities. Cambridge, Mass.: Harvard University Press, 1968.

Recebido em: 11/12/2014

Aceite final em: 20/05/2015 